\title{
KEAUSAN CRANK PIN JOURNAL CRANKSHAFT PADA DIESEL ENGINE GENERATOR DI. MV. KARTINI BARUNA
}

\author{
Tristanto Prasetya ${ }^{a}$, Sarifuddin ${ }^{\mathrm{b}}$ dan Budi Joko Raharjo ${ }^{\mathrm{c}}$ \\ ${ }^{a}$ Taruna (NIT.49124615.T) Program Studi Teknika PIP Semarang \\ ${ }^{b}$ dan cDosen Program Studi Teknika Teknika PIP Semarang
}

\begin{abstract}
ABSTRAK
Crankshaft merupakan komponen mesin yang bekerja mengubah gerak lurus bolakbalik piston dengan perantara batang piston menjadi gerak putar. Untuk mengubahnya, dengan proses sebuah crankshaft membutuhkan pena engkol (crank pin, sebuah bearing tambahan yang diletakkan di bagian ujung batang penggerak pada tiap silinder.

Mengingat pentingnya fungsi crankshaft maka keberadaan komponen mesin tersebut harus dirawat dengan baik. Dalam penelitian ini penulis menggunakan metode fault tree analysis, yaitu metode analisa yang digunakan apabila terdapat suatu kejadian yang tidak diinginkan atau undesired event terjadi pada suatu sistem. Sistem tersebut kemudian dianalisa dengan kondisi lingkungan dan operasional yang ada.

Dengan melaksanakan prosedur tersebut diharapkan sistem operasional diesel generator dapat berfungsi secara normal dan maksimal, sehingga kegiatan pelayaran dan perusahaan tidak mengalami kerugian yang disebabkan terganggunya operasional kapal. Pada akhir bagian penelitian. Penulis menyajikan kesimpulan dan saran.
\end{abstract}

Kata kunci: crankshaft diesel engine generator, keausan crank pin journal

\section{PENDAHULUAN}

\section{A. Latar Belakang}

Pada saat penulis peraktek laut di MV. Kartini Baruna selama 1 tahun 2 bulan 1 hari, sering terjadi masalah pada diesel generator. Diesel generator merupakan permesinan bantu yang berperan penting untuk menghasilkan sumber listrk di kapal. Permasalahan yang sering terjadi adalah turunnya tekanan minyak lumas yang mengakibatkan diesel generator shut down, karena suhu minyak lumas meningkat dan mengakibatkan tekanan minyak lumas turun. Hal ini dicurigai akibat dari filter yang kotor. Ketika penggantian filter ditemukan gram-gram difilter minyak lumas yang mungkin berasal dari crankshaft dan main bearing atau crank pin bearing. Kejadian tersebut menyebabkan sering terjadinya black out ketika kapal manuver, kapal berlayar dan kapal bongkar muat. Ketika kapal di galangan ASL docking Batam dilakukan pembongkaran dan pengecekan pada bagian crankshaft dan ditemukan kondisi crankshaft sudah terkikis atau aus khususnya pada crank pin journal crankshaft.

B. Perumusan Masalah Adapun rumusan masalah penelitian ini adalah sebagai berikut:

1. Faktor-faktor apa saja yang dapat menyebabkan terjadinya keausan pada crank pin journal crankshaft diesel generator?

2. Apa saja dampak yang ditimbulkan dari keausan crank pin journal crankshaft diesel generator?

3. Bagaimana upaya mengatasi keausan pada crank pin journal crankshaft diesel generator? 
Tristanto Prasetya, Sarifuddin dan Budi Joko Raharjo

C. Tujuan Penelitian

Tujuan dari penelitian ini adalah :

1. Untuk mengetahui faktor-faktor penyebab keausan pada crank pin journal crankshaft diesel generator.

2. Untuk mengetahui dampak yang ditimbulkan dari keausan crank pin journal crankshaft diesel generator.

3. Untuk mengetahui upaya mengatasi keausan pada crank pin journal crankshaft.

\section{Manfaat penelitian}

Penelitian ini diharapkan dapat memberi manfaat dan pengetahuan yang berarti bagi pihak-pihak yang terkait dengan dunia pelayaran, dunia ilmu pengetahuan serta bagi individu.

\section{KAJIAN PUSTAKA}

\section{A. Kajian Pustaka}

Crankshaft adalah sebuah bagian pada mesin yang mengubah gerak vertikal / horizontal dari piston menjadi gerak rotasi (putaran). Untuk mengubahnya, dengan proses sebuah crankshaft membutuhkan pena engkol (crankpin), sebuah bearing tambahan yang diletakkan di bagian ujung batang penggerak pada setiap silinder, yang berfungsi untuk untuk mengubah gerak naik turun piston (torak) menjadi gerak putar yang akhirnya dapat menggerakkan roda gila (fly wheel).

Bagian-bagian dari crankshaft yaitu:

1. Main bearing

Bearing yang terletak pada blok mesin sehingga merupakan tumpuan utama bagi crankshaft saat berputar. Disebut main bearing karena bearing ini tidak kemana-mana hanya duduk diam di blok mesin.

2. Crankshaft thrust bearing

Adalah bearing yang didesain untuk menahan beban horisontal yang paralel dengan sumbu poros horizontal.
3. Counter balance weight

Sebagai penyeimbang putaran mesin.

4. Crank pim journal dan main journal Bagian poros engkol yang dihubungkan dengan blok silinder, main journal merupakan crank journal yang terletak di tengah. Pada main journal terdapat bantalan yang disebut dengan bantalan duduk (main bearing), sementara pada main journal oil pada bagian samping juga terdapat bantalan yang disebut dengan metal bulan.

5. Crank pin (pena engkol)

Bagian poros engkol yang akan dihubungkan dengan big end pada connecting rod, crank pin akan dipasangi bantalan yang biasa disebut dengan metal jalan.

6. Crank arm

Bagian pada crankshaft yang berfungsi sebagai penghubung antara crank journal ke crank pin.

\section{B. Kerangka Pikir}

Dalam hal ini terlebih dahulu penulis menggambarkan diagram alur penelitian sebagai berikut:

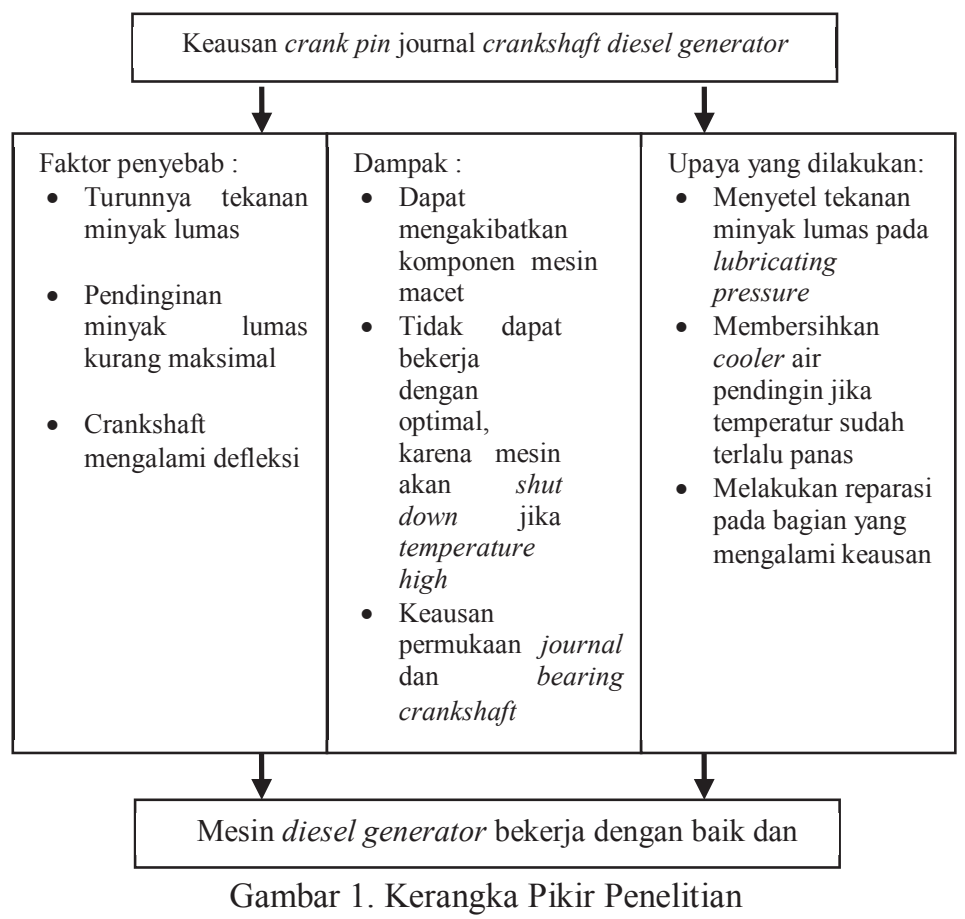




\section{METODOLOGI}

\section{A. Waktu dan Tempat Penelitian}

1. Waktu penelitian

Pada penulisan penelitian ini dilakukan pengkajian dengan menggunakan fakta-fakta dari pengalaman juga pengetahuan yang telah dipadukan dari permasalahan yang penulis lihat dan alami saat melaksanakan praktek laut sebagai engine cadet kurang lebih selama 14 bulan 1 hari. Sign on pada tanggal 11 November 2014 di Tanjung Jati, Jepara Jawa Tengah dan sign off pada tanggal 12 Januari 2016 di Tanjung Jati, Jepara Jawa Tengah. Pada saat penulis melaksanakan penelitian, penulis sedang melaksanakan dinas jaga harian. Pada pelayaran yang ke-13 dari Tanjung Jati, Jepara Jawa Tengah menuju Kalimantan Timur pelabuhan Sangatta Kalimantan Timur, Bontang Kalimantan Timur, dimana hanya dua diesel generator yang beroperasi dan satu diesel generator mengalami kerusakan pada crankshaft yang kondisi pada crank pin journal sudah aus.

2. Tempat penelitian

Pelaksanaan penelitian ini dilakukan selama melaksanakan praktek laut. Adapun nama kapal dan alamat perusahaan:

- Nama kapal : MV. Kartini Baruna

- Tipe kapal : Bulk Carrier

- Nama perusahaan : PT. Ship Management Indonesia

- Alamat : Cilegon highway blok B/5 Jl. Akses tol Cilegon Timur

- Track : Tanjung Jati, Jepara Jawa Tengah, Sangatta Kalimantan Tengah, Sangatta Kalimantan Timur, Bontang Kalimantan Timur
B. Jenis Data

1. Data primer

Data primer merupakan sumbersumber dasar yang merupakan bukti atau saksi utama dari kejadian yang lalu, dimana sumber primer adalah tempat atau gudang penyimpanan yang original dari data sejarah. Dalam hal ini data-data pada penelitian ini diperoleh dengan cara atau metode survey dan terjun secara langsung pada objek penelitian yang diteliti pada waktu di atas kapal, yaitu dengan cara memahami dan mengamati secara langsung di lokasi penelitian.

2. Data sekunder

Data sekunder penelitian ini merupakan dokumentasi dan arsiparsip resmi, yang diusahakan sendiri pengumpulannya oleh penulis. Data ini diperoleh dari dokumentasi yang berkaitan dengan obyek. Data sekunder adalah data yang diperoleh dari sumber tidak langsung yang biasanya berupa bukti dan permasalahan penelitian yang diperlukan sebagai pedoman teoritis dan ketentuan formal dari keadaan nyata dalam observasi.

C. Metode Pengumpulan Data

1. Metode Observasi (Pengamatan)

Observasi adalah suatu teknik pengumpulan data yang dilakukan melalui suatu pengamatan, dengan disertai pencatatan-pencatatan terhadap keadaan atau perilaku obyek sasaran.

Hal-hal yang perlu diperhatikan dalam melaksanakan observasi:

a. Diarahkan pada tujuan tertentu, bukan bersifat spekulatif, melainkan sistematis dan terencana.

b. Dilakukan pencatatan sesegera mungkin, jangan ditangguhkan dengan mengandalakan kekuatan daya ingat. 
Tristanto Prasetya, Sarifuddin dan Budi Joko Raharjo

c. Diusahakan sedapat mungkin, pencatatan secara kuantitatif.

d. Hasilnya harus dapat diperiksa kembali untuk diuji kebenarannya.

2. Dokumentasi

Maksud dari cara ini adalah penulis memperoleh data dengan cara membaca arsip-arsip dan surat-surat serta file-file yang terdapat di kamar mesin. Data-data tersebut merupakan data yang konkrit yang dapat memberikan keterangan nyata yang benar-benar terjadi di atas kapal selama pelayaran, yang mana datadata tersebut telah didokumentasikan dan dilaporkan pada pihak perusahaan.

Pada setiap kapal terdapat dokumendokumen yang berkenaan dengan kapal. Untuk permesinan kapal memiliki dokumen-dokumen tersendiri yang biasa disebut instruction manual book, buku ini memuat antara lain: sistem kerja pesawat, bagian-bagian dari pesawat, serta panduan perawatan.

Dokumen lain yang dibutuhkan diantaranya dokumen perawatan pada low temperature cooler biasanya tercantum pada PMS dan manual book. Dokumen ini sangat berguna pada saat mengalami masalah pada diesel generator.

3. Studi Pustaka

Studi pustaka adalah suatu pembahasan yang berdasarkan pada buku-buku referensi yang bertujuan untuk memperkuat materi pembahasan maupun sebagai dasar untuk menggunakan rumus-rumus tertentu dalam menganalisa dan mendesain suatu struktur. Studi pustaka juga merupakan suatu langkah untuk memperoleh informasi yang relevan dari suatu penelitian terdahulu yang harus dikerjakan dengan topik atau masalah yang akan atau sedang diteliti.

Studi pustaka digunakan untuk memecahkan masalah yang ada, baik untuk menganalisa faktor-faktor dan data pendukung maupun untuk merencanakan konstruksi. Pada bagian ini penulis menguraikan secara global pemakaian rumusrumus dan persamaan yang akan digunakan untuk memecahkan masalah yang ada. Dengan memanfaatkan surat-menyurat, jurnal pengoperasian dan perawatan mesin yang akan membantu penulis dalam penyusunan penelitian ini.

\section{Teknik analisis data}

Analisa adalah proses mencari dan menyusun secara sistematis data yang diperoleh dari hasil catatan lapangan dan dokumentasi dengan cara memilih mana yang penting dan yang akan dipelajari kemudian menarik kesimpulan, sehingga mudah dipahami oleh diri sendiri maupun orang lain. Dalam penelitian ini penulis menganalisa datadata yang diperoleh dari hasil penelitian berupa fakta-fakta yang terjadi di lingkungan, studi pustaka dan juga metode dokumentasi. Kemudian dibandingkan dengan teori yang ada sehingga bisa diberikan solusi untuk masalah tersebut.

Metode yang digunakan penyusun untuk menganalisa data dalam penelitian ini memaparkan metode fault tree analysis (analisa pohon kesalahan) dimana dalam penulisan penelitian ini memaparkan semua kejadian atau peristiwa yang terjadi di kapal dan yang mungkin akan terjadi di atas kapal dengan identifikasi kemungkinankemungkinan yang mempengaruhi kinerja mesin induk.

Analisis pohon kegagalan merupakan analisis induktif yaitu suatu kejadian disebabkan oleh kejadian sebelumnya. Kejadian sebelumnya disebabkan oleh 
kejadian lain lebih lanjut, kegagalan komponen atau kegagalan operator (manusia). Masing-masing kegagalan tersebut dianalisis lebih lanjut penyebabnya sehingga sampai pada kondisi kejadian dasar (basic event).

\section{DISKUSI}

\section{A. Gambaran Umum Obyek Penelitian}

Pada bab ini penulis akan menjelaskan gambaran umum terhadap materi atau obyek yang akan diteliti menggunakan metode fault tree analysis. Obyek yang diteliti adalah keausan crank pin journal crankshaft pada diesel engine generator di MV. Kartini Baruna.

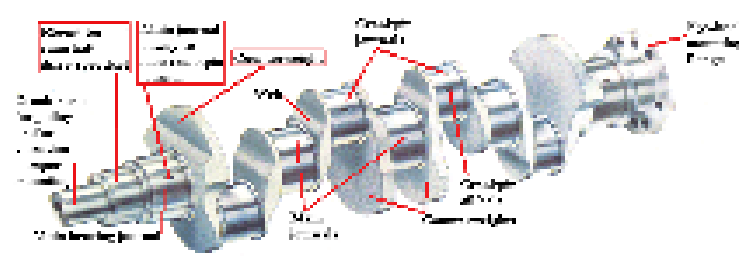

Gambar 2. Bagian-bagian crankshaft

Masalah yang terjadi adalah pada bagian crank pin journal. Pada gambar di atas kita dapat melihat bagian crank pin journal. Terjadi keausan yang mengakibatkan tidak beroperasinya generator sehingga mengganggu pelayaran.

\section{B. Analisa Masalah}

Dengan melakukan analisa kualitatif, maka dapat diketahui bagian mana dari sistem yang gagal dan perlu dilakukan tindakan perbaikan dan pencegahan berdasarkan kegagalan yang ada agar kejadian yang sama tidak terulang. Faktor yang mengakibatkan terjadinya keausan pada crank pin journal antara lain:

1. Terjadi turunnya tekanan minyak lumas dapat diketahui dari pressure gauge yang terdapat pada diesel generator. Pada manual book ditetapkan bahwa tekanan yang diijinkan adalah sekitar 0.4-0.5 Mpa dan akan alarm pada tekanan 0.4 Mpa dan akan stop value pada tekanan 0.3 Mpa. Turunnya tekanan minyak lumas dapat disebabkan oleh temperatur mesin yang tinggi dan mempengaruhi kekentalan minyak lumas tersebut, atau kebocoran pada main bearing, crank pin bearing, dan trust bearing.

Tabel 1. Tekanan Lubricating Oil Diesel Engine Generator

\begin{tabular}{|c|c|c|c|c|}
\hline \multicolumn{5}{|c|}{$\begin{array}{c}\text { Preassure } \\
(\mathrm{Mpa})\end{array}$} \\
\hline \multirow[t]{2}{*}{ Fuel oil } & \multirow[t]{2}{*}{$\begin{array}{l}\text { Engine } \\
\text { inlet }\end{array}$} & $\begin{array}{l}\mathrm{H} \\
\mathrm{O}\end{array}$ & $\begin{array}{l}0.5- \\
1.0\end{array}$ & 0.5 \\
\hline & & $\begin{array}{l}\mathrm{D} \\
\mathrm{O}\end{array}$ & $\begin{array}{l}0.2- \\
0.3\end{array}$ & \\
\hline \multirow[t]{2}{*}{ Lubricating oil } & $\begin{array}{l}\text { Engine } \\
\text { inlet }\end{array}$ & \multicolumn{2}{|c|}{$0.4-0.5$} & $\begin{array}{l}0.4 \\
(0.3)\end{array}$ \\
\hline & $\begin{array}{l}\text { Turbo } \\
\text { charger } \\
\text { inlet- } \\
\text { outlet }\end{array}$ & \multicolumn{2}{|c|}{$0.2-0.5$} & 0.2 \\
\hline
\end{tabular}

Tabel di atas merupakan ketentuan pada manual book. Berdasarkan analisa di atas maka dapat dicari penyebab-penyebab turunnya tekanan minyak lumas, yaitu :

a. Tingginya temperatur mesin;

b. Kebocoran pada system;

c. Filter oli kotor.

2. Pendinginan minyak lumas kurang optimal

Pada sistem pendinginan minyak lumas digunakan media pendingin air tawar pada cooler tipe plat. Pada sistem pendinginan ini, media air tawar yang berada di dalam mesin, didinginkan menggunakan media air laut. Beberapa masalah yang ditemukan pada pendinginan minyak lumas ini adalah kurang turunnya temperatur air tawar karena beberapa plat pada sisi air laut terdapat banyak kerang-kerang kecil yang mengakibatkan terbuntunya plat sisi 
Tristanto Prasetya, Sarifuddin dan Budi Joko Raharjo

air laut pada cooler dan turunnya tekanan air laut yang masuk ke dalam cooler auxiliary engine.

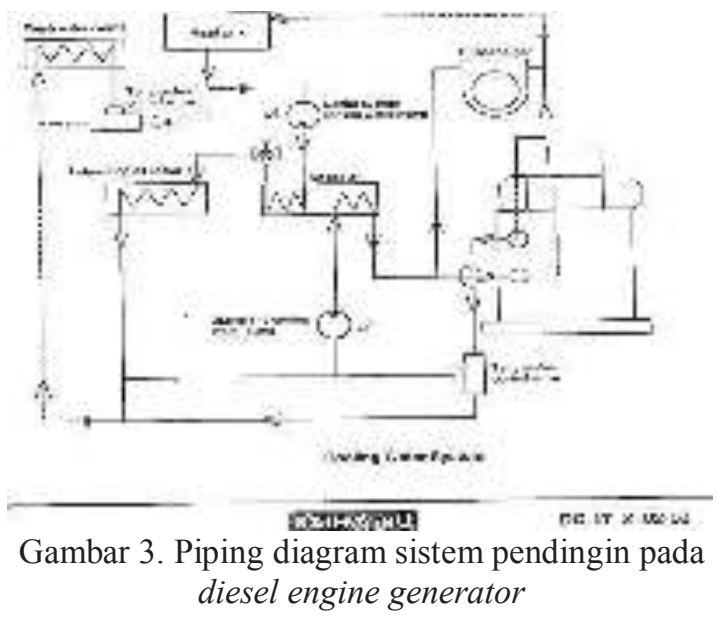

Berdasarkan analisa di atas maka dapat dicari penyebab-penyebab mengapa pendinginan minyak lumas kurang optimal, yaitu :

a. Plat pada sisi air laut terdapat banyak kotoran;

b. Lubricating oil temperature sudah tidak bisa automatic.

3. Crankshaft mengalami defleksi

Defleksi poros engkol secara umum, ini adalah hal yang sangat fatal untuk sebuah penggerak kapal terutama pada bagian propulsi kapal. Suatu poros engkol yang berada di dalam suatu komponen mesin induk adalah salah satu pendukung utama yang berhubungan langsung dengan putaran atau rotasi dari propulsi kapal. Jika terjadi pada poros engkol, akan mengakibatkan kecepatan (Vs) yang direncanakan pada kapal tidak sesuai.

Berdasarkan analisa di atas maka dapat dicari penyebab-penyebab mengapa distribusi udara terhambat, yaitu :

a. Keausan pada main atau crank pin bearing;

b. Baut pengikat crank pin bearing tidak kencang.
Dengan mengetahui penyebab mengakibatkan terjadinya keausan crank pin journal diesel engine generator di MV. Kartini Baruna, seorang engineer dapat langsung melakukan perbaikan pada bagian sistem yang mengalami kerusakan. Dari hasil penelitian yang penulis dapatkan dan penulis paparkan dalam analisa hasil penelitian di atas, ada beberapa masalah yang penulis anggap perlu untuk dibahas.

C. Pembahasan masalah

1. Faktor Penyebab

a. Turunnya tekanan minyak lumas Penyebab turunnya tekanan minyak lumas dapat disebabkan oleh beberapa hal, yaitu :

1) Tingginya temperatur mesin yang diakibatkan oleh sistem pendinginan yang kurang optimal. Adanya panas yang berlebihan dari diesel generator, sehingga membuat minyak pelumas tersebut terlalu encer atau viscosity berkurang.

2) Kebocoran pada sistem pelumasan

Di bawah ini dipaparkan gambar diagram piping sistem pelumasan. Dari gambar di bawah ini kita dapat melihat jalur pelumasan dan dapat diperoleh pada bagian-bagian yang melewati komponenkomponen tersebut.

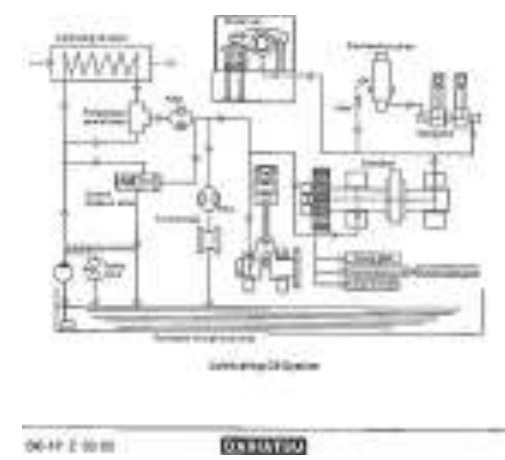

Gambar 4. Piping diagram lubricating oil 
Penulis melakukan pengecekan pada bagian-bagian yang dilewati oleh minyak lumas, dengan cara menghidupkan priming pump dan ditemukan kebocoran pada trust bearing. Terlihat minyak lumas keluar pada bagian samping trust bearing. Pada crank pin bearing terlihat minyak lumas terlalu besar karena pada crank pin bearing kondisinya sudah keluar dari dudukan connecting rod.

3) Filter oli kotor

Filter pada dasarnya berfungsi untuk menyaring kotorankotoran yang terdapat pada sistem. Filter yang kotor juga dapat berpengaruh pada tekanan minyak lumas, yang nantinya mengakibatkan tekanan minyak lumas turun. Saat penulis melakukan penelitian, ditemukan adanya kotoran, endapan lumpur dan gram-gram pada filter oli. Dari beberapa faktor di atas menyebabkan turunnya tekanan minyak lumas yang seharusnya 0.4-0.5 Mpa menjadi di bawah ketentuan.

b. Pendinginan munyak lumas kurang optimal

Pada sistem pendinginan minyak lumas, minyak lumas didinginkan oleh jacket cooling. Jacket cooling didinginkan kembali pada cooler yang terpisah dengan diesel engine melalui media air laut. Tekanan air laut pada cooler inlet dan outlet tidak boleh jauh berbeda, karena dapat berpengaruh pada penyerapan panas jacket cooling diesel engine. Pada cooler pendingin jacket cooling sering melakukan pembersihan plat-plat sisi air laut dikarenakan pelayaran yang lebih lama di pelabuhan. Pada sisi air laut cepat kotor karena kerangkerang kecil di laut. Hal tersebut menyebabkan seringnya tersumbatnya celah plat pada sisi air laut dan menyebabkan temperature jacket cooling diesel engine menjadi tinggi dan suhu minyak lumas ikut naik. Penyebab pendinginan minyak lumas kurang optimal dapat disebabkan oleh beberapa hal, yaitu :

1) Plat pada sisi air laut terdapat banyak kotoran dimana untuk mendinginkan temperature minyak lumas harus melewati beberapa sistem.

Di bawah ini akan dijelaskan bagaimana proses pendinginan minyak lumas.

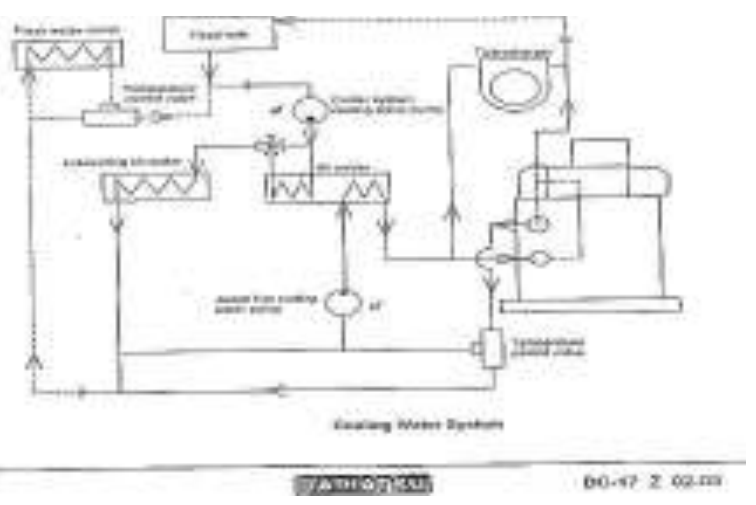

Gambar 5. Piping diagram sistem pendingin pada diesel engine generator

Untuk mendinginkan temperature minyak lumas temperature jacket cooling juga berpengaruh karena yang mendinginkan minyak lumas adalah jacket cooling. Untuk mendapatkan temperature jacket cooling yang baik adalah 36-38 kondisi tekanan air laut inlet dan outlet pada cooler water harus sesuai dan tidak boleh berbeda jauh. 
Tristanto Prasetya, Sarifuddin dan Budi Joko Raharjo

2) Lubricating oil temperature valve sudah tidak bisa automatic

Lubricating oil temperature valve adalah alat untuk mengatur temperatur minyak lumas. Prinsip kerja valve mengembalikan beberapa minyak lumas kembali ke dalam kalter sebelum berjalan ke sistem pelumasan. Sehingga ketika minyak lumas hampir mencapai hight temperature maka valve akan bekerja. Valve akan menutup aliran minyak lumas ke dalam kalter dan mengalirkkan lebih banyak minyak lumas ke dalam system.

Dibawah ini adalah gambar Lubricating oil temperature valve.

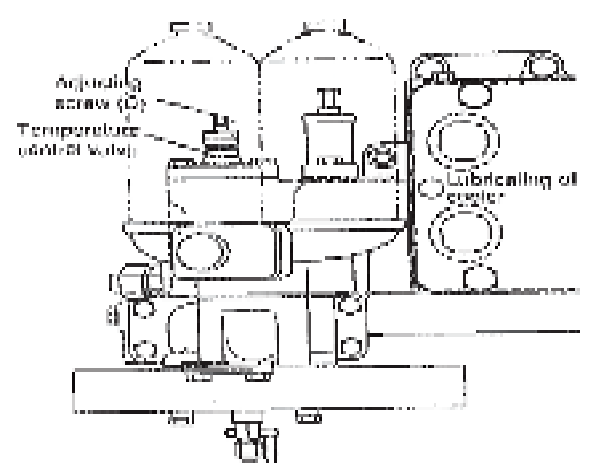

Gambar 6. Lubricating oil temperature control valve

Pada waktu pengecekan pada lubricating oil temperature valve sudah dilakukan penyetelan dan tidak mengubah temperatur minyak lumas, dan waktu over haul lubricating oil temperature valve ditemukan karet sudah rusak.

c. Crankshaft mengalami defleksi

Setelah melakukan pengecekan pada bagian-bagian di atas penulis juga melakukan pengambilan defleksi pada crankshaft yang dilakukan pada saat kapal docking. Pengambilan defleksi dilakukan oleh Masinis III yang bertanggung jawab atas diesel engine generator. Pada dasarnya defleksi diambil untuk mengetahui kelurusan pada crankshaft. Di bawah ini akan dijelaskan mengenai cara pengambilan defleksi pada crankshaft diesel engine generator.

Langkah-langkah pengukuran:

1) Mempersiapkan spesial tools;

2) Putar roda gila sampai 30 sesudah titik mati bawah. Ini adalah posisi EB;

3) Pasang defleksi gauge dan atur posisi jarum dial gange ke 0 .

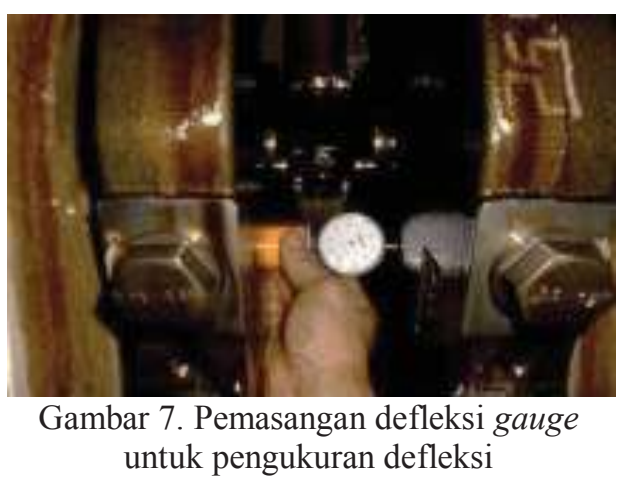

4) Putar dengan pelan roda gila searah putaran mesin. Tulis dan baca di posisi crank pin $\mathrm{E}$, T, P dan PB.

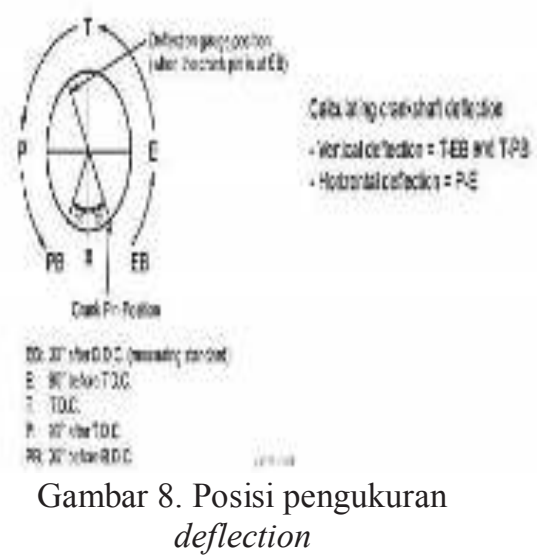


5) Jika defleksi meningkat setiap kali diukur, crankshaft bearing utama mungkin dikenakan. Jika defleksi meningkatkan tiba-tiba hanya dalam satu silinder, bantalan utama yang sesuai mungkin tak beraturan usang. Dalam kasus ini periksa bagian yang relevan.

6) Jika defleksi diukur saat mesin panas, hasilnya akan bervariasi sebagian besar tergantung pada suhu mesin pada saat pengukuran. Pengukuran tidak dapat diandalkan. Menurut hasil pengujian defleksi kira-kira 2 / 10.000 untuk 3 / $10.000 \mathrm{x}$ stroke (bawah ditutup).

Di bawah ini adalah data pengambilan defleksi:

\section{CRANK SHAFT DEFLECTION RECORD}

SHIP NAME $\quad:$ MV.KARTINI
BARUNA
DATE : $11^{\mathrm{TH}}$ AUG 2015
ENGINE TYPE : DAIHATSU
CRANKCASE,
TEMP ${ }^{\circ} \mathrm{C}: 44^{\circ} \mathrm{C}$ JOURNAL
RADIUS $\quad 180$
DISPLACEMENT, M/T 0
STROKE $\quad 280$
DRAFT, FORE, M: -
TOTAL ROUNING HRS : 4688
AFTER, M $\quad:-$
MEAN, M:-

Tabel 2. Hasil pengukuran defleksi

\begin{tabular}{|c|c|c|c|c|c|}
\hline CYL. NO. & 1 & 2 & 3 & 4 & 5 \\
\hline POS. BP & 0 & 0 & 0 & 0 & 0 \\
\hline P & -0.75 & -1.75 & -2.5 & 1.25 & 0.25 \\
\hline T & -0.5 & -1.5 & -7 & -1 & 0 \\
\hline S & 0 & 1 & 4 & -1.5 & 0.75 \\
\hline BS & -0.5 & 1.5 & -1.5 & -1 & 0 \\
\hline B & -0.25 & 0.75 & -0.75 & -0.5 & 0 \\
\hline T+B & -0.75 & -1 & -2.25 & -1.5 & 0 \\
\hline P+S & -0.75 & -0.75 & 1.5 & 0.75 & 1 \\
\hline
\end{tabular}

Dari data pengambilan crankshaft defleksi dapat disimpulkan bahwa pada posisi cylinder no 3 mengalami kerapatan defleksi paling tinggi hal ini dapat menyebabkan getaran yang tinggi.

2. Dampak yang ditimbulkan

a. Mesin diesel generator tidak dapat bekerja

Hal ini mengakibatkan kekhawatiran pada pelayaran karena hanya 2 dari 3 diesel generator yang bekerja di atas kapal. Tidak bisa diesel generator beroperasi secara terus menerus karena diesel generator yang lain juga memerlukan perawatan rutin. Pelaksanaan perawatan juga harus mematikan mesin untuk mengecek bagian-bagian pada motor diesel.

b. Mengalami masalah pada waktu perawatan

Jika salah satu diesel generator dari 3 generator rusak maka 2 diesel generator harus tetap hidup pada waktu pelayaran. Jika salah satu diesel genarator dari 2 yang beroprasi maka salah satu harus dimatikan, maka hanya 1 generator yang bekerja. Banyak permesinan bantu yang harus dimatikan karena diesel generator mempunyai beban maksimun untuk menompang permesinan bantu lainnya.

c. Gangguan pada keselamatan

Besar kemungkinan terjadi black out karena hanya 1 diesel generator yang bekerja pada saat pelayaran. Bisa mengakibatkan terjadinya kecelakaan pelayaran, kecelakaan kerja, kelelahan, stres dan keselamatan crew.

3. Upaya yang dilakukan agar keausan crank pin journal crankshaft tidak 
Tristanto Prasetya, Sarifuddin dan Budi Joko Raharjo

terjadi.

a. Mengoptimalkan tekanan minyak lumas

Pada kalter minyak lumas sudah diperiksa dan kondisi level minyak lumas pada batas optimal. Upaya di bawah ini dilakukan untuk mengoptimalkan tekanan minyak lumas sehingga minyak lumas dapat melumasi dan bersirkulasi secara baik. Sehingga diharapkan ketikan tekanan minyak lumas sudah optimal, dapat mengurangi gaya gesek yang besar pada crankshaft, khususnya pada crank pin journal. Berikut ini adalah beberapa cara untuk mengoptimalkan tekanan minyak lumas:

1) Menambah volume minyak lumas;

2) Membersihkan cooler minyak lumas dan cooler jacket cooling agar viscosity minyak lumas tidak turun, sehingga tekanan dapat meningkat;

3) Mengatasi minyak lumas yang keluar dari crank pin dan thrust bearing yang berlebih dengan cara mengganti;

4) Menyetel lubricating oil temperature;

5) Mengganti filter minyak lumas dengan yang bersih sebelum tekanan yang tidak diijinkan;

6) Melakukan penyetelan pada lubricating oil temperature dan lubricating oil pressure.

7) Melakukan pengecekan baut pengikat connecting rod setiap satu bulan sekali

Upaya ini dilakukan untuk menghindari berkurangnya kekencangan baut pengunci / pengikat yang diharapkan dengan melakukan upaya ini dapat menghindari terjadi gesekan yang berlebih yang dapat mengakibatkan keausan. b. Melakukan reparasi pada crank pin bearing dan juga pada crank pin journal

Upaya ini dilakukan untuk menghindari keausan yang berlebih yang bisa menyebabkan kerusakan pada crankshaft. Di bawah ini adalah upaya reparasi yang dilakukan.

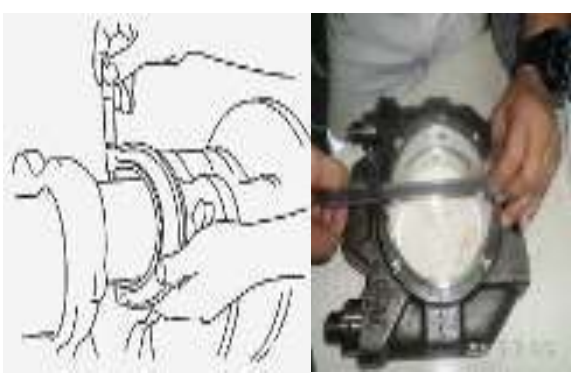

Gambar 9. Mengukur diameter crank pin journal dan crank pin bearing

\section{PENUTUP}

\section{A. Kesimpulan}

Setelah dilakukan penelitian dan analisa keausan crank pin journal crankshaft pada diesel generator dengan metode fault tree analysis di MV. Kartini Baruna, maka penulis mengambil kesimpulan sebagai berikut:

1. Faktor penyebab terjadi keausan pada crank pin journal crank shaft diesel engine generator adalah kurangnya tekanan sistem pelumasan, pada baut pengunci connecting rod kekencangannya berkurang, dan pada crankshaft mengalami defleksi.

2. Dampak yang dapat ditimbulkan dari keausan pada crank pin journal crankshaft diesel engine generator adalah mesin diesel generator tidak dapat bekerja, mengalami masalah pada waktu perawatan, gangguan pada keselamatan. Dampak tersebut dapat membawa efek buruk terhadap pelayaran dan crew kapal.

3. Upaya yang dilakukan untuk mencegah keausan pada crank pin journal crankshaft diesel engine 
generator adalah menjaga tekanan minyak lumas selalu optimal, pemeriksaan baut-baut pengikat, melakukan penanganan agar crankshaft tidak mengalami defleksi.

\section{B. Saran}

Setelah memperhatikan kesimpulan tersebut di atas, maka penulis memberikan saran yang sekiranya dapat bermanfaat:

1. Melakukan perawatan, pengecekan, penggantian sesuai dengan jadwal rencana perawatan pada setiap peralatan pada crankshaft;

2. Segera melakukan upaya untuk mengatasi keausan pada crank pin journal crankhaft diesel engine generator yaitu dengan melakukan reparasi pada crankshaft atau pada main bearing dan crank pin bearing agar masalah tidak semakin parah;

3. Melakukan perawatan terhadap pada crankshaft diesel generator sangat penting karena memiliki peran dalam menjaga umur crankshaft. Apabila perawatan yang dilakukan dengan baik dan benar maka diharapkan crankshaft diesel generator dapat bekerja dengan normal dan dalam waktu yang lama.

\section{DAFTAR PUSTAKA}

Hidayat, Wahyu. 2012. Motor Bensin Modern. Jakarta : Rineka Cipta

Handoyo, Jusak Johan. 2014. Mesin Penggerak Utama Motor Diesel. Jakarta

Nazir. 2014. Metodologi Penelitian Pengumpulan Data

Sugiyono. 2008. Metode Penelitian Bisnis. Jakarta : Alfabeta

Kristiansen. 2015. Metode Fault Tree Analysis

Daihatsu Diesel Engine Operation Manual
Rowen, Alan L. and R. D. Jacobs. 2014. Modern Marine Engineer's Manual, Volume II Third Edition. Amerika 